\title{
Reference memory effects of distributed practice on radial maze learning by rats
}

\author{
DAVID G. ELMES, JOHN C. WILLHITE, and G. BRIAN BAUER \\ Washington and Lee University, Lexington, Virginia 24450
}

\begin{abstract}
Rats received 11 trials on five different problems that required them to learn which four arms on an eight-arm radial maze were baited. Half the rats had an intertrial interval of $45 \mathrm{sec}$ (massed practice), and the other half had an intertrial interval of $10 \mathrm{~min}$ (distributed practice). Test trials allowed an examination of performance unconfounded by the length of the intertrial interval. Performance improved within a problem, but learning to learn was not very substantial. Distributed practice resulted in significantly fewer reference memory errors (extraproblem intrusions) than did massed practice, but the conditions of practice had no effect on working memory errors (repetitions of correct responses).
\end{abstract}

It has been argued that discrimination learning is supported by both a transient working memory and a more permanent reference memory (Honig, 1978; Olton, 1978). Reference memory includes the general instructions for the task and is relevant to performance over many trials. Working memory, on the other hand, is applicable to performance on a single discrimination trial. With regard to discriminating which four arms of an eight-arm radial maze are baited, reference memory may be described as pertaining to the general facts of the situation (that reinforcement appears at the distal end of the arms, etc.), as well as to the particular four arms that are baited. Working memory in the radial maze task refers to an updated record of within-trial performance. In operational terms, reference memory on the eight-arm maze is assessed by noting the frequency with which unbaited or extraproblem alleys are entered. Working memory is assessed by counting repeated entries of an already visited baited alley on a single trial. In the jargon of verbal learning, reference memory is indexed by extralist intrusions, and working memory is indexed by within-list intrusions of responses already correctly given on that trial.

Since the distinction between working and reference memory has proved useful in studying delayed matching to sample behavior (Honig, 1978) and the physiological substrates of radial maze performance (Olton, 1978), this distinction may be valuable in assessing the effects of other variables in discrimination learning. In the present experiment, we examined the effects of massed and distributed practice on the memories presumed to underlie radial maze performance.

The major reasons for investigating the hoary question of distributed-practice effects are that it is not at

Aspects of these data were discussed at the meetings of the Psychonomic Society, San Antonio, November 1978. Requests for reprints should be sent to David G. Elmes, Department of Psychology, Washington and Lee University, Lexington, Virginia 24450. all certain how the conditions of practice will influence animal discrimination learning (e.g., Mackintosh, 1974), nor is it entirely clear how distribution of practice affects the memory processes underlying other behaviors (e.g., Crowder, 1976). So, half the animals in the present experiment received massed practice (the intertrial interval was $45 \mathrm{sec}$ ) and half received distributed practice (the intertrial interval was $10 \mathrm{~min}$ ) on problems that required them to learn which four of the eight arms of the maze were baited. All animals received a test trial $24 \mathrm{~h}$ after the final training trial so that performance could be assessed unconfounded by the length of the intertrial interval.

\section{METHOD}

\section{Subjects}

Ten male albino rats derived from the Sprague-Dawley strain served as subjects. They were about 110 days old at the start of the experiment and were maintained at $85 \%$ of their free-feeding weights. They were randomly assigned to groups.

\section{Apparatus}

The elevated eight-arm maze had wooden arms and a wooden central platform. Radiating out from the octagonal central platform, which measured $34 \mathrm{~cm}$ at its longest dimensions, were eight $96.5-\mathrm{cm}$-long arms, which were $9 \mathrm{~cm}$ wide. The arms were spaced equidistantly about the platform, and each arm had 6-cm-high Plexiglas sides. The entire maze was on legs so that its top surface was $78.5 \mathrm{~cm}$ above the floor. The $45-\mathrm{mg}$ Noyes pellet reinforcers were placed at the distal end of the arm in a 2-cm-deep well, which prohibited the animals from seeing the reinforcement when they were at the beginning of an arm.

\section{Design}

Half the rats had an intertrial interval of $45 \mathrm{sec}$ (massed practice), and the other half had an intertrial interval of $10 \mathrm{~min}$ (distributed practice). Each rat received 11 trials on five different problems, each of which required them to learn to go to four of the eight arms.

\section{Procedure \\ Seven days of pretraining involved a total of $35 \mathrm{~min}$ of free exploration of the maze. During pretraining, eight Noyes pellets}


were scattered about the platform on each animal's daily exploration, but none of the arms was baited.

Following pretraining, training began and occurred on 3 successive days for a particular problem. Days 1 and 2 involved five trials on the same problem, and Day 3 ( $24 \mathrm{~h}$ later) had a single test trial. During the next 3-day testing cycle, each animal received a new problem. This cyclical training and testing procedure was repeated until each animal had been tested on five different problems. Note that the single trial on Day 3 occurred at approximately the same time after the final training trial for all animals regardless of the intertrial interval within Days 1 and 2.

On Days 1 and 2 the following occurred during the 45 -sec intertrial interval of the massed-practice group: After their fourth reward, they were returned to their home cage, the maze was quickly swabbed with disinfectant, the appropriate alleys were rebaited, and then that animal received its next trial. The distributed-practice animals spent $10 \mathrm{~min}$ in their home cages between successive trials on Days 1 and 2. During that time, other animals were being tested, and the maze was swabbed and baited appropriately between the run of each animal. On Day 3 each subject received a single trial, and after an animal had completed its trial, the maze was swabbed and baited for the next one.

Five different four-arm problems were selected for testing. At a given point in the experiment, one animal from each practice group was assigned to a particular problem. The animals were then rotated through these problems so that each problem was tested five times in each practice condition by the end of the experiment.

The animals were allowed a maximum of $5 \mathrm{~min}$ to complete a trial. They were free to enter or reenter any alley, which means that a correction training procedure was used. The animals were removed from the maze when they had obtained the fourth pellet or when $5 \mathrm{~min}$ had elapsed, whichever came first. Timing was via a stopwatch, and times were recorded to the nearest second. Each alley entered and the order in which the alleys were entered were recorded.

\section{RESULTS}

Since a correction procedure was used, and since some animals failed to receive all four rewards on some trials, a relative performance measure seemed appropriate. Overall performance was indexed by the following ratio: $(C-E / C+E)(100)$, where $C$ represents correct responses, and $\mathrm{E}$ stands for total errors (both extraproblem entries and repeated entries of correct alleys). Working memory was indexed by the following ratio: $(C-R / C+R)(100)$ where $C$ stands for correct responses, and $\mathrm{R}$ represents repeated entries of a baited alley from which the animal had already received the reinforcement. Reference memory was determined by the following ratio: $(\mathrm{C}-\mathrm{I} / \mathrm{C}+\mathrm{I})(100)$, where $\mathrm{C}$ stands for correct responses, and I stands for entries into unbaited arms. The .05 level of confidence is used throughout this report.

The most pertinent results appear in Figure 1, which depicts the test-trial (Day 3) performance summed over problems for the massed- and distributed-practice groups. Separate analyses of each dependent measure indicated that there were no Massed-Distribued by Problems interactons on the test trials. Overall performance and reference memory performance were both better under distributed practice than under massed practice $[\mathrm{F}(1,8)=7.13, \mathrm{MSe}=672.33$, and $\mathrm{F}(1,8)=$ $10.48, \mathrm{MSe}=961.64$, respectively] . Working memory performance was not appreciably influenced by the conditions of practice $(\mathrm{F}=1.63)$.

Day-by-day performance on each problem, summed over the five trials on Days 1 and 2, appears in Table 1 . Note that overall performance increased over days $[\mathrm{F}(2,16)=9.62, \mathrm{MSe}=110.31]$ and problems $[\mathrm{F}(4,32)$ $=3.32, \mathrm{MSe}=1,437.44]$, although the latter improve-

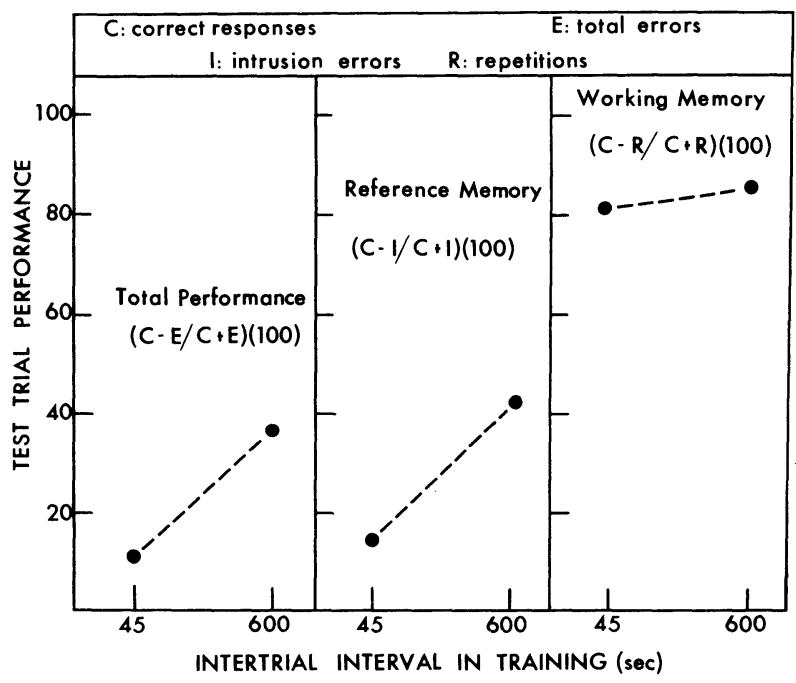

Figure 1. Test-trial performance summed over problems for the massed- and distributed-practice groups.

Table 1

Mean Performance Each Day on Each Problem Summed Over Trials for the Massed-and Distributed-Practice Groups

\begin{tabular}{|c|c|c|c|c|c|c|c|c|c|c|c|c|c|c|c|c|}
\hline \multirow{3}{*}{$\begin{array}{c}\text { Performance } \\
\text { Measure }\end{array}$} & \multirow{3}{*}{$\begin{array}{c}\text { Practice } \\
\text { Group }\end{array}$} & \multicolumn{3}{|c|}{ Problem 1} & \multicolumn{3}{|c|}{ Problem 2} & \multicolumn{3}{|c|}{ Problem 3} & \multicolumn{3}{|c|}{ Problem 4} & \multicolumn{3}{|c|}{ Problem 5} \\
\hline & & \multicolumn{3}{|c|}{ Day } & \multicolumn{3}{|c|}{ Day } & \multicolumn{3}{|c|}{ Day } & \multicolumn{3}{|c|}{ Day } & \multicolumn{3}{|c|}{ Day } \\
\hline & & 1 & 2 & $\mathrm{~T}$ & 1 & 2 & $\mathrm{~T}$ & 1 & 2 & $\mathrm{~T}$ & 1 & 2 & $\mathrm{~T}$ & 1 & 2 & $\mathrm{~T}$ \\
\hline$(C-E / C+E)(100)$ & $\begin{array}{l}\text { Distributed } \\
\text { Massed }\end{array}$ & $\begin{array}{l}-17 \\
-12\end{array}$ & $\begin{array}{l}-2 \\
-6\end{array}$ & $\begin{array}{l}22 \\
16\end{array}$ & $\begin{array}{l}-5 \\
-5\end{array}$ & $\begin{array}{l}29 \\
17\end{array}$ & $\begin{array}{l}48 \\
13\end{array}$ & $\begin{array}{r}8 \\
-6\end{array}$ & $\begin{array}{l}13 \\
26\end{array}$ & $\begin{array}{r}32 \\
2\end{array}$ & $\begin{array}{r}19 \\
.4\end{array}$ & $\begin{array}{l}28 \\
24\end{array}$ & $\begin{array}{r}45 \\
8\end{array}$ & $\begin{array}{r}18 \\
9\end{array}$ & $\begin{array}{r}29 \\
-5\end{array}$ & $\begin{array}{l}31 \\
17\end{array}$ \\
\hline$(C-R / C+R)(100)$ & $\begin{array}{l}\text { Distributed } \\
\text { Massed }\end{array}$ & $\begin{array}{l}61 \\
62\end{array}$ & $\begin{array}{l}63 \\
71\end{array}$ & $\begin{array}{l}75 \\
73\end{array}$ & $\begin{array}{l}72 \\
65\end{array}$ & $\begin{array}{l}88 \\
86\end{array}$ & $\begin{array}{l}84 \\
75\end{array}$ & $\begin{array}{l}82 \\
55\end{array}$ & $\begin{array}{l}80 \\
81\end{array}$ & $\begin{array}{r}100 \\
87\end{array}$ & $\begin{array}{l}86 \\
73\end{array}$ & $\begin{array}{l}87 \\
87\end{array}$ & $\begin{array}{l}87 \\
82\end{array}$ & $\begin{array}{l}81 \\
69\end{array}$ & $\begin{array}{l}79 \\
75\end{array}$ & $\begin{array}{l}92 \\
87\end{array}$ \\
\hline$(C-I / C+I)(100)$ & $\begin{array}{l}\text { Distributed } \\
\text { Massed }\end{array}$ & $\begin{array}{l}6 \\
3\end{array}$ & $\begin{array}{r}10 \\
7\end{array}$ & $\begin{array}{l}32 \\
11\end{array}$ & $\begin{array}{l}3 \\
4\end{array}$ & $\begin{array}{l}33 \\
23\end{array}$ & $\begin{array}{l}60 \\
20\end{array}$ & $\begin{array}{r}14 \\
8\end{array}$ & $\begin{array}{l}17 \\
31\end{array}$ & $\begin{array}{r}32 \\
6\end{array}$ & $\begin{array}{r}23 \\
9\end{array}$ & $\begin{array}{l}33 \\
29\end{array}$ & $\begin{array}{l}45 \\
12\end{array}$ & $\begin{array}{r}16 \\
9\end{array}$ & $\begin{array}{r}27 \\
9\end{array}$ & $\begin{array}{r}23 \\
0\end{array}$ \\
\hline
\end{tabular}

Note $-C=$ correct responses, $E=$ total errors, $I=$ intrusion errors, $R=$ repetitions, $T=$ test . 
ment was not particularly dramatic. Working memory also increased over days $[\mathrm{F}(2,16)=3.63, \mathrm{MSe}=609.49]$ and problems $[\mathrm{F}(4,32)=2.86, \mathrm{MSe}=414.55]$. Reference memory improved across days $[F(2,16)=9.88$, $\mathrm{MSe}=390.80$ ], especially for the distributed-practice subjects $[F(2,16)=6.09, \mathrm{MSe}=390.80]$. There was only a moderate and nonsignificant increase in reference memory across successive problems $(F=1.92)$. No other main effects or interactions were significant in these analyses.

\section{DISCUSSION}

The test-trial results shown in Figure 1 indicate that the major effect of distribution of practice on radial maze behavior is to enhance reference memory, the general rules governing the task and specifying the loci of reinforcements. Working memory, the within-trial log of responding, was unaffected by the conditions of practice. It is not precisely clear how these results can be reconciled with the numerous theories that have been devised to account for practice effects in human learning (see Crowder, 1976), nor are there any theoretical endeavors from the animal learning literature that seem appropriate to complex discrimination learning (e.g., Mackintosh, 1974).

What has occurred to us with regard to interpreting the results should be regarded as a preliminary formulation. Since our data indicate strong reference memory effects associated with distributed practice, accounts that emphasize short-term processes, such as inattention (Crowder, 1976), are probably irrelevant. However, eliminating this and similar possibilites leaves numerous other accounts in contention. A plausible candidate is a notion that has recently received strong support from human learning studies (Elmes, in press; Thios \& D'Agostino, 1976, Note 1). The gist of this theory is as follows: A repeated trial on a task serves as a trigger or cue for retrieving information about the events that occurred on the previous trial. As the separation between trials increases, two things may happen: (1) The more difficult retrieval demanded by spaced trials allows the subject to practice the sort of retrieval that will be required on test trials, and (2) this difficult, task-relevant retrieval may demand or encourage extra mnemonic effort on the part of the animal. Either or both of these effects of distributed trials should enhance test-trial performance. Admittedly, this retrieval hypothesis is post factum, speculative, and may be irrelevant to the discriminatory behavior of rodents. The notion does offer some testable predictions, however, and additional work on practice effects in animal discrimination learning may lend it some plausibility. Moreover, further tests of the retrieval hypothesis in the context of discrimination learning may link the hypothesis to other memory-oriented viewpoints that have been developed to account for simpler learning phenomena (e.g., Capaldi, 1971).

Some of the other results should be considered briefly. The extent of learning to learn across problems was not very extensive and was limited mainly to improvements in working memory. The major reason for minimal learning to learn probably is due to the small number of training trials allotted to each problem. Very few animals regularly attained perfect performance on a problem, so more extensive training may have yielded better performance on later problems.

\section{REFERENCE NOTE}

1. Thios, S. J., \& D'Agostino, P. R. Repetition and studyphase retrieval in an incidental memory paradigm. Paper presented at the meetings of the Psychonomic Society, Washington, D.C., November 1977.

\section{REFERENCES}

CAPAldi, E. J. Memory and learning: A sequential viewpoint. In W. K. Honig \& P. H. R. James (Eds.), Animal memory. New York: Academic Press, 1971.

Crowde R, R. G. Principles of learning and memory. Hillsdale, N.J: Erlbaum, 1976.

Elmes, D. G. Retrieval processes in human memorization. Virginia Journal of Science, in press.

HonIG, W. K. Studies of working memory in the pigeon. In S. H. Hulse, H. F. Fowler, \& W. K. Honig (Eds.), Cognitive aspects of animal behavior. Potomac, Md: Erlbaum, 1978.

MaCkintosh, N. J. The psychology of animal learning. London: Academic Press, 1974.

Olton, D. S. Characteristics of spatial memory. In S. H. Hulse, H. F. Fowler, \& W. K. Honig (Eds.), Cognitive aspects of animal behavior. Potomac, Md: Erlbaum, 1978.

Thios, S. J., \& D'Agostino, P. R. Effects of repetition as a function of study-phase retrieval. Journal of Verbal Learning and Verbal Behavior, 1976, 15, 529-536.

(Received for publication May 3, 1979.) 